\title{
ACHIEVING COMPETITIVE ADVANTAGE THROUGH PRACTICING TQM TOOLS IN PHARMACEUTICALS COMPANY
}

\author{
Niamat Ullah Ibne Hossain ${ }^{1 *}$, Farjana Nur ${ }^{2}$ and Md. Ahasan Habib ${ }^{3}$ \\ ${ }^{1}$ Department of Mechanical Engineering \\ ${ }^{2,3}$ Department of Industrial Engineering and Management \\ Khulna University of Engineering \& Technology, Khulna-9203, Bangladesh \\ *Corresponding e-mail: niamat.hossain@gmail.com, farjana.mitu08@gmail.com
}

\begin{abstract}
In order to survive in a competitive market, improving quality and productivity of Product or process is a must for any company. And in case of pharmaceutical industry, effective quality assurance policy implementation is the most important goal. The main objective of this paper is to apply the Total Quality Management (TQM) tools in a pharmaceutical company and prove its advantage. Here Control Chart, Fishbone diagram, EWMA were used and the control limits were improved. This activity resulted in more perfect control limit recommendations which actually capable of reducing the material cost. The TQM perspective views quality as the pivotal purpose of the organization. Present review attempts to furnish a wide overview of the TQM tools leading to quality improvement of Pharmaceuticals Company.
\end{abstract}

Keywords: TQM, Control Chart, Fishbone Diagram, EWMA Control Chart, Competitive advantage.

\section{INTRODUCTION}

Total Quality Management (TQM) is one of quality oriented approaches that many organizations adopt. It is generally acknowledged that manufacturing companies need to be quality oriented in conducting their business to survive the business world ${ }^{1}$. TQM is an integrated management philosophy and a set of practices that emphasizes top management commitment, customer focus, supplier relationship, benchmarking, quality-oriented training, employee focus, zero-defects, process improvement, and quality measurement ${ }^{2,3}$. As defined by ISO-"TQM is a management approach of an organization, centered on quality, based on the participation of all its members and aiming at longterm success through customer satisfaction, and benefits to all members of the organization and to society."

TQM, combined with effective leadership, results in an organization doing the right things right, first time ${ }^{4}$. The application of TQM and its tools \& techniques within a pharmaceutical industry not only improves its processes and Quality of products, but also adds a new step towards the overall improvement of the whole organization.

Actually in this paper, the detailed analysis was done on a pharmaceutical company. Almost all pharmaceutical companies use a highly improved technology and manufacturing processes. Hence they serve products of almost zero defects. But with the goal of achieving zero defects, they may not be so conscious of the production cost which can be reduced by applying TQM tools. Cost is one of the important dimensions of quality which is to be balanced with it for increased productivity and profit.

\section{LITERATURE REVIEW}

As the application of TQM tools \& techniques within a pharmaceutical industry improves its processes and Quality of products with the overall improvement of the whole organization, it is important to introduce the tools.

These are Pareto chart, Histogram, Fishbone diagram, Flow chart, Check point, Scatter diagram, Control chart, EWMA control chart, Poke Yoke, Loss function, PDCA cycle, KAIZEN, Tree diagram etc. ${ }^{5}$. Pareto chart is one of the total quality management tools and usually used during the define stage in six sigma. A simple rule, Pareto, $20 \%$ issues causes $80 \%$ results. This means, $80 \%$ of problems come from 20 of reasons. $80 \%$ of results come from $20 \%$ of work. $80 \%$ of costs come from $20 \%$ of spent area...and so on.

One of the Total Quality Management Tools is the Histogram. This graph is used to show frequency distributions. It looks very much like a bar chart.

This chart graphs data distributions. If we have numerical, variable, continuous data we can use the chart. The chart organizes and sorts the data. It shows the data in a pictorial format.

Fish Bone Diagram also called Cause-and-Effect Diagram or Ishikawa Diagram. The Cause and Effect diagram identifies many possible causes for an effect or a problem. It can used to structure a brainstorming session because it immediately sorts ideas into key categories ${ }^{6,7}$.

Control charts, also known as Shewhart charts or process-behavior charts, in statistical process control are tools used to determine whether a manufacturing or business process is in a state of statistical control. To determine whether a process should undergo a formal examination for quality-related problems is the actual purpose. Another chart, called EWMA 
control chart is used to find out the inherent problems in the process when the process is actually in control.

\section{CASE STUDY}

Here all relevant data of this paper were collected from SQUARE PHARMACEUTICALS LIMITED, the leading manufacturer of pharmaceuticals in Bangladesh. SQUARE Cephalosporin's Limited (SCL) was built as a separate manufacturing plant at the kaliakoir site for Cephalosporine Antibiotics in 2006. They manufacture Cephalosporin's Antibiotics in various pharmaceutical dosage forms comprising tablets, capsules, dry powder for suspensions, pediatric drops etc. Among the huge list of their products Cefotil 500 Tablet is chosen for the detailed study.

Cefotil (Cefuroxime) is a well-characterized and effective antibacterial agent, which has broadspectrum bactericidal activity against a wide range of common pathogens. Cefotil 500 Tablet is a quick moving product but it need not to produce per day. Monthly almost eight batch is produced to meet the market demand. The batch size of Cefotil 500 Tablet is 65,000 tablets. The individual weight data of Cefotil 500 tablet is found from different inspection bench.

Table 1. Weight data table of Cefotil 500 Tablet

\begin{tabular}{|c|c|c|c|c|}
\hline $\begin{array}{c}\text { Sample } \\
1\end{array}$ & $\underset{2}{\text { Sample }}$ & $\begin{array}{c}\text { Sample } \\
3\end{array}$ & $\begin{array}{c}\text { Sample } \\
4\end{array}$ & $\begin{array}{c}\text { Sample } \\
5\end{array}$ \\
\hline 924 & 932 & 954 & 956 & 954 \\
\hline 956 & 944 & 942 & 951 & 944 \\
\hline 954 & 947 & 963 & 933 & 963 \\
\hline 948 & 952 & 955 & 946 & 945 \\
\hline 973 & 959 & 941 & 954 & 939 \\
\hline 955 & 961 & 954 & 976 & 952 \\
\hline 973 & 983 & 940 & 962 & 955 \\
\hline 949 & 970 & 953 & 947 & 943 \\
\hline 959 & 963 & 958 & 959 & 949 \\
\hline 959 & 937 & 947 & 948 & 958 \\
\hline 950 & 960 & 956 & 962 & 949 \\
\hline 945 & 953 & 959 & 964 & 957 \\
\hline 959 & 963 & 971 & 962 & 955 \\
\hline 936 & 954 & 955 & 961 & 950 \\
\hline 970 & 959 & 947 & 952 & 960 \\
\hline 955 & 964 & 940 & 956 & 964 \\
\hline 975 & 952 & 968 & 955 & 958 \\
\hline 951 & 952 & 957 & 956 & 951 \\
\hline 957 & 944 & 960 & 954 & 946 \\
\hline 950 & 952 & 966 & 959 & 953 \\
\hline
\end{tabular}

They have some known defects as milling defects, compression defects, coating, thickness variation, blister packing etc. Among them almost all are in negligible amount in their view but this paper focus on the limits why certain defects are always negligible to them. All the defects are actually in negligible amounts and control limits used by them for the quality concern is also perfect. But in case of weight variation and thickness variation, they do not pay much heed in setting good control limits or other statistical quality control tools. This in turn increases its material cost (though tablet performance is perfect in work).

Here sample no is, $\mathrm{N}=20$

Mean weight of every 100 Tablets $=$ Weight $(\mathrm{mg})$ of 100 tablets $/ 100$

Mean weight of every 100 Tablets $=95443 / 100 \mathrm{mg}$

$$
=954.43 \mathrm{mg}
$$

Here the range for the weight of tablets are, Upper Limit $=966 \mathrm{mg}$, Lower Limit $=874 \mathrm{mg}$

The mean weight is assumed as the average weight of the 100 tablets. I.e. $954.43 \mathrm{mg}$.

The acceptable range is, Mean $\pm 5 \%$ And not more than two shall deviate from this limit as well as the critical limit for acceptance is , Mean $\pm 10 \%$ and none shall deviate from this limit.

Now standard deviation is calculated using

$$
\begin{aligned}
\text { Variance, } \sigma^{2} & =\frac{\sum_{\mathrm{i}=1}^{5}(\mathrm{Xi}-\mu)^{\wedge} 2}{\mathrm{~N}-1} \\
& =9458.51 /(100-1) \\
& =95.54 \mathrm{mg}
\end{aligned}
$$

where, $\sigma=$ Standard deviation

$$
\begin{aligned}
\mathrm{i} & =1 \text { to } 5 \\
\mathrm{Xi} & =\text { weight of sample } \mathrm{i} \\
\mathrm{N} & =\text { Data No / Observation No } \\
\mu & =\text { Mean weight }
\end{aligned}
$$

So, Standard Deviation, $\sigma=\sqrt{ }($ variance $)$

$$
=\sqrt{ } 95.54=9.77 \mathrm{mg}
$$

Hence for the used range, upper limit is $+1.18 \sigma \&$ lower limit is 8.23 б. $1^{\mathrm{st}}$ acceptance limit is $\pm 4.86 \sigma$ and $2^{\text {nd }}$ acceptance limit is almost $\pm 9.76 \sigma$.

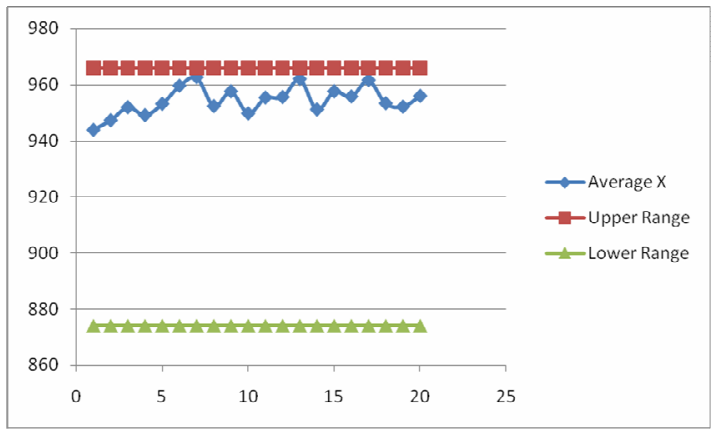

Figure 1. Graph showing Range limits of SCL 


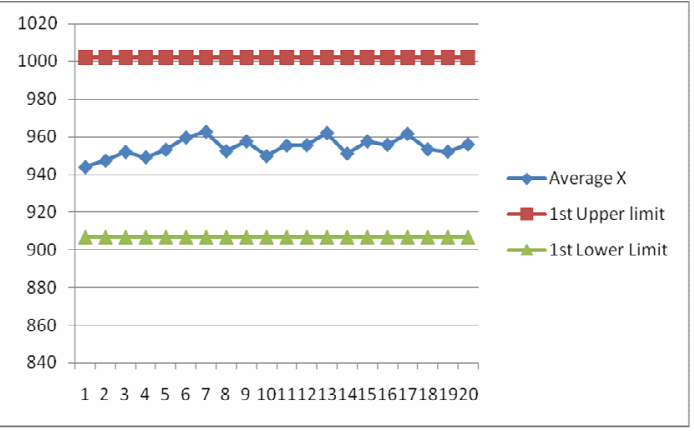

Figure 2. Graph showing $1^{\text {st }}$ acceptance limits of SCL

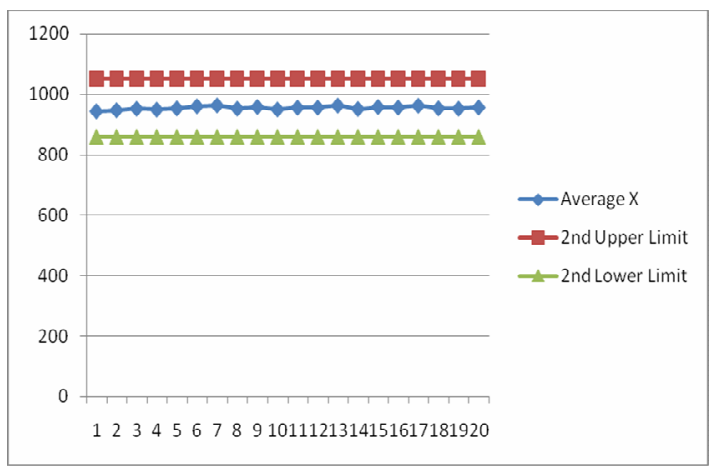

Figure 3. Graph showing $2^{\text {nd }}$ acceptance limits of SCL

Table 2. Thickness data table of Cefotil 500 Tablet

\begin{tabular}{|l|l|l|l|l|}
\hline $\begin{array}{l}\text { Sample } \\
\mathbf{1}\end{array}$ & $\begin{array}{l}\text { Sample } \\
\mathbf{2}\end{array}$ & $\begin{array}{l}\text { Sample } \\
\mathbf{3}\end{array}$ & $\begin{array}{l}\text { Sample } \\
\mathbf{4}\end{array}$ & $\begin{array}{l}\text { Sample } \\
\mathbf{5}\end{array}$ \\
\hline 6.28 & 6.42 & 6.41 & 6.39 & 6.37 \\
\hline 6.21 & 6.38 & 6.37 & 6.41 & 6.28 \\
\hline 6.38 & 6.40 & 6.39 & 6.30 & 6.39 \\
\hline 6.40 & 6.37 & 6.39 & 6.40 & 6.39 \\
\hline 6.32 & 6.41 & 6.37 & 6.27 & 6.39 \\
\hline 6.44 & 6.37 & 6.39 & 6.39 & 6.37 \\
\hline 6.41 & 6.40 & 6.39 & 6.39 & 6.39 \\
\hline 6.34 & 6.38 & 6.39 & 6.39 & 6.36 \\
\hline
\end{tabular}

Here sample no is, $\mathrm{N}=8$

Mean thickness of every 40 Tablets $=$ thickness

$(\mathrm{mm})$ of 40 tablets $/ 40=254.89 / 40$

$$
=6.37225 \mathrm{~mm}
$$

Here the range for the thickness of tablets are, Lower range $=5.95 \mathrm{~mm}$, Upper range $=6.55 \mathrm{~mm}$

The mean thickness is assumed as the average thickness of the 40 tablets, i.e. $6.37225 \mathrm{~mm}$

The standard deviation of the thickness data is obtained using equation (i) and (ii) as,

$$
\sigma=0.04610398
$$

Hence for the used range, upper limit is $+3.85 \sigma \&$ lower limit is $-9.15 \sigma$. This is shown in below figure.

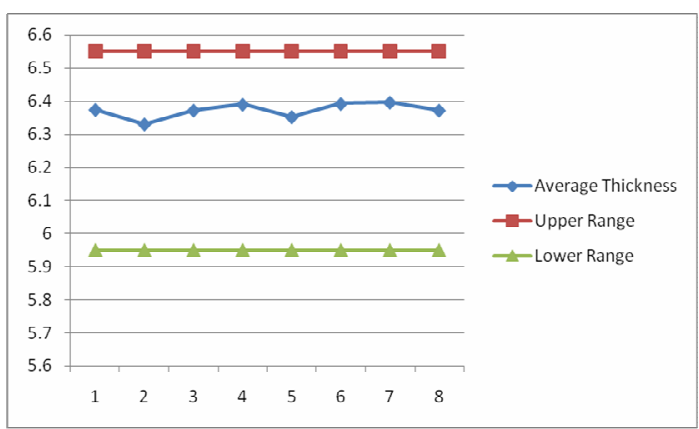

Figure 4. Graph showing range limits for thickness data

The control limits the Square Cephalosporin's Limited follows are shown in above calculations . The data reveals some important facts about their quality control tasks.

1. The weight and thickness of tablets are not same and the mean is based upon the obtained data average. Hence there is no standardized mean as well as mean may vary and can assume any value that is very much undesirable according to the sense of QUALITY.

2. The standard deviation obtained from these data is 9.77 for weight \& 0.046 for thickness. Operating with these deviations respectively causes selection of wider control limit. Which may in turn show the in control situation when the process is actually out of control.

3.The next fact that which is almost clear to all is they do not maintain any $\sigma$ limit which should obviously be narrowed for maintaining QUALITY and decreasing their material cost.

\section{POSSIBLE IMPROVEMENTS In case of weight data}

The first recommendation is to set a unique Mean. Let, $\mu=945 \mathrm{mg}$

The standard deviation obtained also is very large which can be narrowed to further quality improvement. The standard deviation may be , $\sigma=5$

Hence the first acceptance range is

Upper Limit $=945+945 \times 5 \%=992.25 \mathrm{mg}$ \& Lower Limit $=945-945 \times 5 \%=897.75 \mathrm{mg}$

The critical limit for acceptance is Mean $\pm 10 \%$ i.e. Upper Limit $=945+945 \times 10 \%=1039.5 \mathrm{mg}$ \& Lower Limit $=945+945 \times 10 \%=850.5 \mathrm{mg}$

Here the limits are also wide but upper limits are less than before and constant as mean is constant. This can be improved by changing their concept of acceptable range in terms of $\%$ of mean to standard deviation concept.

Control chart using standard deviation concept The control limits for the control chart are, 
Upper control limit $(\mathrm{UCL})=\mu+\mathrm{L} \sigma$

$$
\begin{aligned}
& =945+3 \times 5 \\
& =960 \mathrm{mg}
\end{aligned}
$$

Control Limit $(\mathrm{CL})=\mu=945 \mathrm{mg}$

Lower control limit $(\mathrm{LCL})=\mu-\mathrm{L} \sigma$

$$
\begin{aligned}
& =945-3 \times 5 \\
& =930 \mathrm{mg}
\end{aligned}
$$

where, $\mu=$ Mean i.e. 945

$\sigma=$ Standard Deviation i.e. $5 \mathrm{mg}$ (as recommended) $\mathrm{L}=$ Distance of the control limits from center line. In most cases for quality improvement $\mathrm{L}$ is considered as 3. Hence the limits become $3 \sigma$ Control Limit.

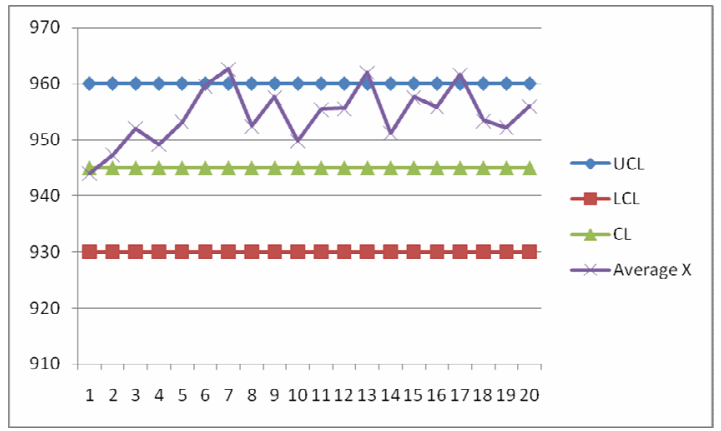

Figure 5. Control Chart using standard deviation

Another control chart (X-bar and $R$ chart)

\begin{tabular}{|c|c|c|c|c|c|c|c|}
\hline observation no & $\mathrm{X} 1$ & $\mathrm{X} 2$ & $\mathrm{X} 3$ & $\mathrm{X} 4$ & X5 & average $x$ & $X R=X_{\max }-X_{\min }$ \\
\hline 1 & 924 & 932 & 954 & 956 & 954 & 944 & 32 \\
\hline 2 & 956 & 944 & 942 & 951 & 944 & 947.4 & 14 \\
\hline 3 & 954 & 947 & 963 & 933 & 963 & 952 & 30 \\
\hline 4 & 948 & 952 & 955 & 946 & 945 & 949.2 & 10 \\
\hline 5 & 973 & 959 & 941 & 954 & 939 & 953.2 & 34 \\
\hline 6 & 955 & 961 & 954 & 976 & 952 & 959.6 & 24 \\
\hline 7 & 973 & 983 & 940 & 962 & 955 & 962.6 & 43 \\
\hline 8 & 949 & 970 & 953 & 947 & 943 & 952.4 & 27 \\
\hline 9 & 959 & 963 & 958 & 959 & 949 & 957.6 & 14 \\
\hline 10 & 959 & 937 & 947 & 948 & 958 & 949.8 & 22 \\
\hline 11 & 950 & 960 & 956 & 962 & 949 & 955.4 & 13 \\
\hline 12 & 945 & 953 & 959 & 964 & 957 & 955.6 & 19 \\
\hline 13 & 959 & 963 & 971 & 962 & 955 & 962 & 16 \\
\hline 14 & 936 & 954 & 955 & 961 & 950 & 951.2 & 25 \\
\hline 15 & 970 & 959 & 947 & 952 & 960 & 957.6 & 23 \\
\hline 16 & 955 & 964 & 940 & 956 & 964 & 955.8 & 24 \\
\hline 17 & 975 & 952 & 968 & 955 & 958 & 961.6 & 23 \\
\hline 18 & 951 & 952 & 957 & 956 & 951 & 953.4 & 6 \\
\hline 19 & 957 & 944 & 960 & 954 & 946 & 952.2 & 16 \\
\hline 20 & 950 & 952 & 966 & 959 & 953 & 956 & 16 \\
\hline & & & & & & 954.43 & 21.55 \\
\hline
\end{tabular}

Another control chart can be developed for variables. The chart is $\bar{x}$ - R chart is given in Table 3 .

Table 3. Chart for calculating X-bar and R-bar

Hence the limit becomes for X-bar chart

$$
\begin{aligned}
\mathrm{UCL}_{\times}=\overline{\bar{X}}+A_{2} * \overline{\mathrm{R}} & =954.43+0.577 \times 21.55 \\
& =966.86 \\
\mathrm{CL}=954.43 & \\
\mathrm{LCL}_{x}=\overline{\bar{x}}-\mathrm{A}_{2} * \overline{\mathrm{R}} & =954.43-0.577 \times 21.55 \\
& =941.99
\end{aligned}
$$

For $\mathrm{R}$ chart

$$
\begin{aligned}
& U C L_{R}=D_{4} * \bar{R}=2.004 \times 21.55=43.186 \\
& C L=21.55 \\
& L C L_{R}=D_{3} * \bar{R}=0 \times 21.55=0
\end{aligned}
$$

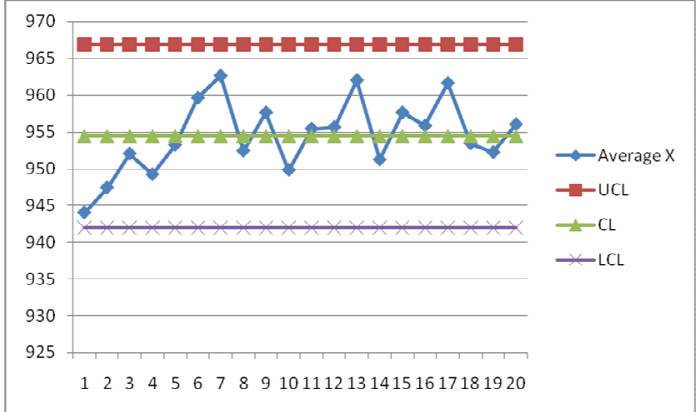

Figure 6. X- bar Control Chart

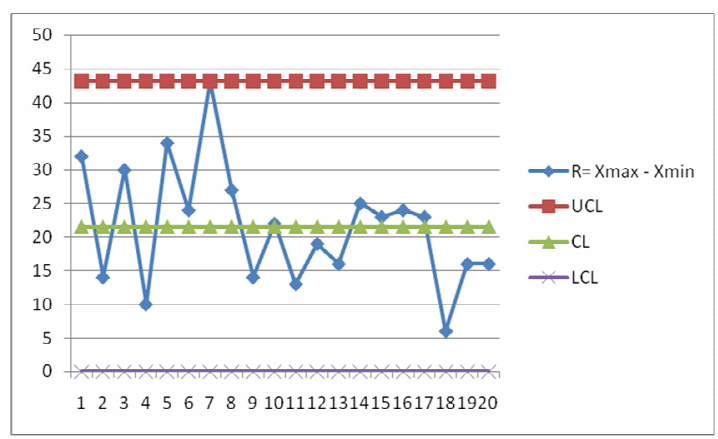

Figure 7. R Control Chart

\section{The EWMA Control Chart}

The EWMA is a special type of control chart which is capable of finding amy hidden errors of process.

The chart is built by a huge amount of calculations. For SQUARE datas the EWMA requires below calculations.

For $\mathrm{i}=1$

Control Limit $=\overline{\bar{X}}=954.43$

$$
\begin{aligned}
& \mathrm{UCL}=\overline{\overline{\mathrm{X}}}+\mathrm{L} \times \frac{\mathrm{S}}{\sqrt{\mathrm{n}}} \times \sqrt{(\lambda /(2-\lambda))} \sqrt{\left[1-(1-\lambda)^{2 \mathrm{i}}\right]} \\
& =954.43+3 \times 9.77 \sqrt{ }[(0.25 /(2-0.25)) \times\{1-(1- \\
& \left.\left.0.25)^{\wedge}(2 \times 1)\right\}\right]
\end{aligned}
$$

$\lambda=0.25$ assumed where $(0<\lambda<1)$

$(\mathrm{S} / \sqrt{ } \mathrm{n})=\sigma=9.77$

Now, For observation 1

$$
\begin{aligned}
\mathrm{Z}_{\mathrm{i}-1} & =\overline{\overline{\mathrm{X}}}=954.43 \\
\mathrm{Z}_{\mathrm{i}} & =\lambda \overline{\mathrm{x}_{\mathrm{i}}}+(1-\lambda) \mathrm{Z}_{\mathrm{i}} \\
& =0.25 \times 944+(1-0.25) \\
& =951.82
\end{aligned}
$$


Table 4. Z \& limit Calculation Table

\begin{tabular}{|r|r|r|r|r|r|}
\hline observation no & Mean & SECOND PART & Z value & UCL & LCL \\
\hline 1 & 954.4 & 1.638151082 & 951.82 & 956.1 & 952.8 \\
\hline 2 & 954.4 & 2.047688852 & 950.72 & 956.5 & 952.4 \\
\hline 3 & 954.4 & 2.245466129 & 951.04 & 956.7 & 952.2 \\
\hline 4 & 954.4 & 2.349410654 & 950.58 & 956.8 & 952.1 \\
\hline 5 & 954.4 & 2.405906758 & 951.23 & 956.8 & 952 \\
\hline 6 & 954.4 & 2.437110346 & 953.32 & 956.9 & 952 \\
\hline 7 & 954.4 & 2.454488045 & 955.64 & 956.9 & 952 \\
\hline 8 & 954.4 & 2.464209147 & 954.83 & 956.9 & 952 \\
\hline 9 & 954.4 & 2.469660452 & 955.52 & 956.9 & 952 \\
\hline 10 & 954.4 & 2.47272153 & 954.09 & 956.9 & 952 \\
\hline 11 & 954.4 & 2.474441722 & 954.42 & 956.9 & 952 \\
\hline 12 & 954.4 & 2.475408804 & 954.71 & 956.9 & 952 \\
\hline 13 & 954.4 & 2.475952622 & 956.54 & 956.9 & 952 \\
\hline 14 & 954.4 & 2.476258468 & 955.2 & 956.9 & 952 \\
\hline 15 & 954.4 & 2.476430489 & 955.8 & 956.9 & 952 \\
\hline 16 & 954.4 & 2.476527246 & 955.8 & 956.9 & 952 \\
\hline 17 & 954.4 & 2.47658167 & 957.25 & 956.9 & 952 \\
\hline 18 & 954.4 & 2.476612283 & 956.29 & 956.9 & 952 \\
\hline 19 & 954.4 & 2.476629502 & 955.27 & 956.9 & 952 \\
\hline 20 & 954.4 & 2.476639188 & 955.45 & 956.9 & 952 \\
\hline & & & & \\
\hline
\end{tabular}

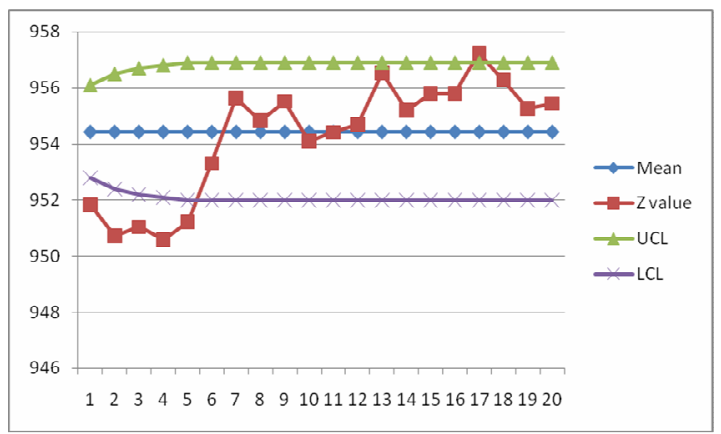

Figure 8. EWMA Control Chart

\section{In case of thickness data}

As the weight data, here the first recommendation is to set a unique Mean and standard deviation also. Let, $\mu=6.35 \mathrm{~mm}$ And $\sigma=.04$

Here control charts using standard deviation concept, X-bar \& R chart, EWMA control charts may be used for setting good control limits.

\section{Control chart using standard deviation concept}

The control limits for the control chart are-

Upper Control limit $=\mu+\mathrm{L} \sigma=6.35+3 * 0.04$

$$
=6.47 \mathrm{~mm}
$$

Lower control limit $=\mu-\mathrm{L} \sigma=6.35-3 * 0.04$

$$
=6.23
$$

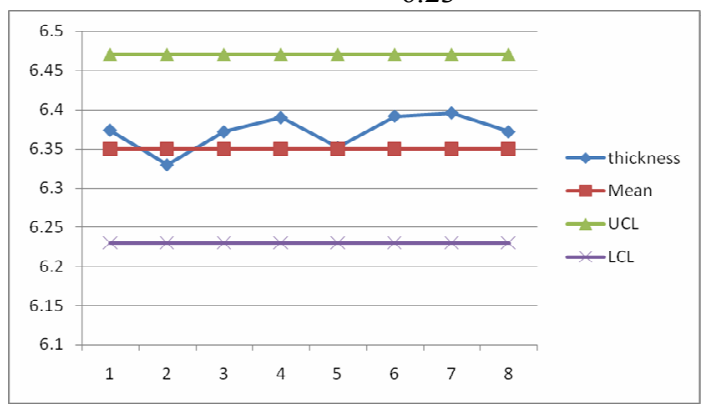

Figure 9. Control Chart using standard deviation for thickness data

\section{$\mathrm{X}$-bar and $\mathrm{R}$ chart}

$\mathrm{X}$-bar and $\mathrm{R}$ chart can also be constructed.

\begin{tabular}{|c|c|c|c|c|c|c|c|}
\hline Obs No -1 & $x 1$ & $\times 2$ & $\times 3$ & $\times 4$ & $\nabla$ & J Average & $x \max -x_{\min }=$ \\
\hline 1 & 6.28 & 6.42 & 6.41 & 6.39 & 6.37 & 6.374 & 0.14 \\
\hline & 6.21 & 6.38 & 6.37 & 6.41 & 6.28 & 6.33 & 0.2 \\
\hline 3 & 6.38 & 6.4 & 6.39 & 6.3 & 6.39 & 6.372 & 0.1 \\
\hline 4 & 6.4 & 6.37 & 6.39 & 6.4 & 6.39 & 6.39 & 0.03 \\
\hline 5 & 6.32 & 6.41 & 6.37 & 6.27 & 6.39 & 6.352 & 0.14 \\
\hline 6 & 6.44 & 6.37 & 6.39 & 6.39 & 6.37 & 6.392 & 0.07 \\
\hline & 6.41 & 6.4 & 6.39 & 6.39 & 6.39 & 6.396 & 0.02 \\
\hline & 6.34 & 6.38 & 6.39 & 6.39 & 6.36 & 6.372 & 0.05 \\
\hline & & & & & & 6.37225 & 0.09375 \\
\hline
\end{tabular}

Table 5. Chart for calculating X-bar and R-bar

For X-bar char-

$\mathrm{UCL}_{x}=\overline{\overline{\mathrm{X}}}+\mathrm{A}_{2} * \overline{\mathrm{R}}=6.37225+.577 * .09375=6.4263$

$\mathrm{CL}=6.37225$

$\mathrm{LCL}_{\times}=\overline{\mathrm{X}}-\mathrm{A}_{2} * \overline{\mathrm{R}}=6.37225-.577 * .09375=6.3182$

And for R chart-

$U C L_{\mathrm{R}}=\mathrm{D}_{4} * \overline{\mathrm{R}}=2.004 * .09375=.187875$

$\mathrm{CL}=.09375$

$\mathrm{LCL}_{\mathrm{R}}=\mathrm{D}_{\mathrm{3}} * \overline{\mathrm{R}}=0 * .09375=0$

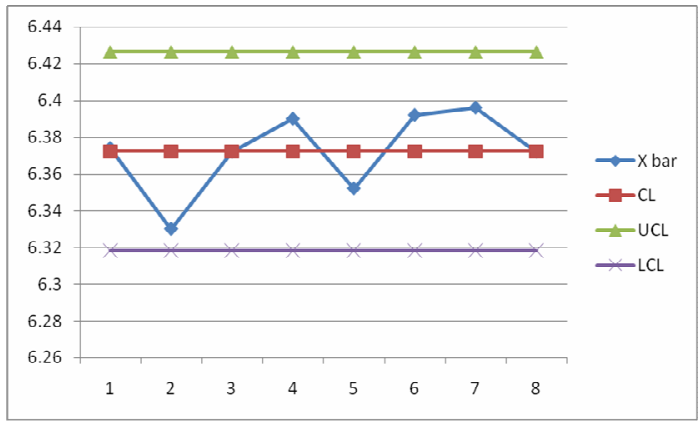

Figure 10. X bar chart for thickness data

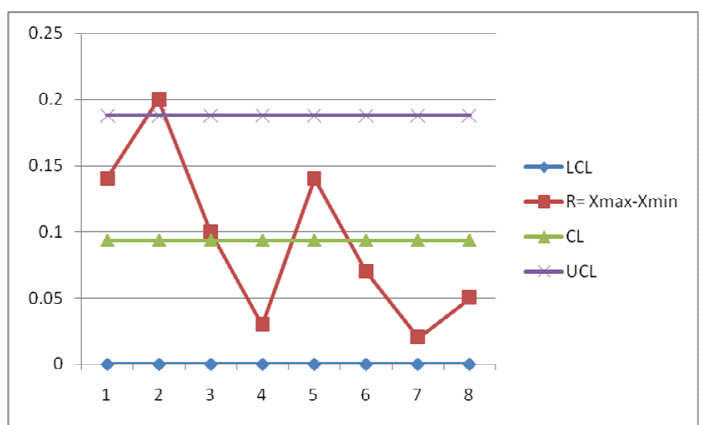

Figure 11. R chart for thickness data

\section{The EWMA Control Chart}

As like as calculations of EWMA control chart for weight data, the control limit calculations are for observation no 1-

Control Limit $=\overline{\bar{X}}=6.37225$

$$
\mathrm{UCL}=\overline{\overline{\mathrm{X}}}+\mathrm{L} \frac{\mathrm{S}}{\sqrt{\mathrm{n}}} \sqrt{\frac{\lambda}{2-\lambda}\left[1-(1-\lambda)^{2 \mathrm{i}}\right]}
$$




$$
\begin{aligned}
\mathrm{UCL}_{1}= & 6.37225+3 \times 0.046 \sqrt{ }[(0.25 /(2-0.25)) \times\{1- \\
& \left.\left.(1-0.25)^{\wedge}(2 \times 1)\right\}\right]
\end{aligned}
$$

$\lambda=0.25$ assumed where $(0<\lambda<1)$

$(\mathrm{S} / \sqrt{ } \mathrm{n})=\sigma=9.77$

Now, For observation 1

$\mathrm{Z}_{\mathrm{i}-1}=\overline{\overline{\mathrm{X}}}=6.37225$

$\mathrm{Z}_{\mathrm{i}}=\lambda \overline{\mathrm{x}_{\mathrm{i}}}+(1-\lambda) \mathrm{z}_{\mathrm{i}}$

$=0.25 \times 6.374+(1-0.25) * 6.37225$

$=6.37688$

Table 6. Chart for calculating UCL, LCL and Z

\begin{tabular}{|r|l|l|l|l|}
\hline \multicolumn{7}{|c|}{ Xbar } & Mean & \multicolumn{2}{|l|}{ V value } & UCL & \multicolumn{1}{l|}{ LCL } \\
6.374 & 6.37225 & 6.37688 & 6.37996 & 6.36454 \\
6.33 & 6.37225 & 6.36202 & 6.38189 & 6.36261 \\
\hline 6.372 & 6.37225 & 6.36451 & 6.38282 & 6.36168 \\
\hline 6.39 & 6.37225 & 6.37088 & 6.38331 & 6.36119 \\
\hline 6.352 & 6.37225 & 6.36616 & 6.38358 & 6.36092 \\
\hline 6.392 & 6.37225 & 6.37262 & 6.38372 & 6.36078 \\
\hline 6.396 & 6.37225 & 6.37847 & 6.38381 & 6.36069 \\
6.372 & 6.37225 & 6.37685 & 6.38385 & 6.36065 \\
\hline
\end{tabular}

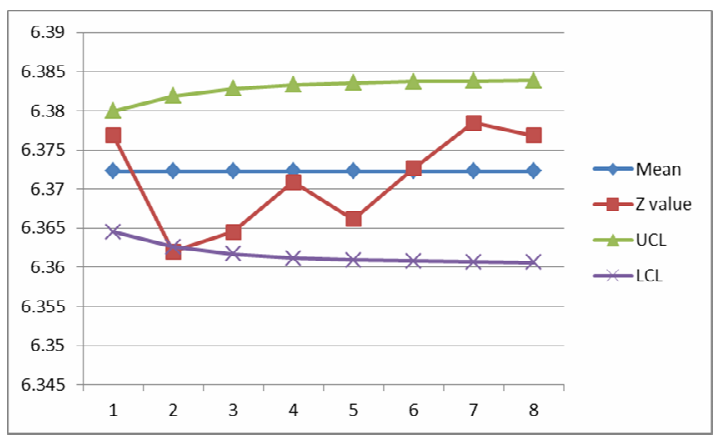

Figure 12. EWMA Control Chart for thickness

\section{ANALYSIS OF OBTAINED CHARTS}

The Control Charts and other charts including EWMA Control Charts shows that the datas belong to a large range. In different charts different circumstances are obvious-

1. The range charts shows the datas are within the limit. But if we concentrate on the graph, it is clear that most of the datas are near to the upper range. Whereas they are far apart from lower range. It is desired for any process that data are to be clustered near the midlevel between two ranges. So that fault should be overcome by the process.And a more suitable range must be set.

2. The next graph of their (SCL's) calculated acceptance limit shows the very wider control limit.

3. The third graph shows the process acceptance limit is more than before.
4. The Control Chart for standard deviation shows a large amount of data falls beyond the control limit in case of weight data. Hence for those points process needs to be improved.

5. Another Control Chart (X-bar and $\mathrm{R}$ chart) shows process within control limit but some points approaching towards the UCL \& LCL. So the process needs to be improved to cluster the points towards CL.

6. The EWMA Control chart shows more improved control limit based on existing data. The limit is narrower, hence some points go beyond the acceptance limit in both case. So it is sure that if the process is more improved such that, all the data exists between the EWMA control limits then it is a highly reliable and improved process.

\section{IMPROVEMENT BY FISHBONE DIAGRAM}

There are some problems in Pharmaceutical companies, but these are very infrequent as occurs once in every six month or once in a year. So it can be said pharmaceutical companies are very much improved and quality focused. But here in this paper it is shown that they do not pay much heed on usage of excess material as a result the weights of antibiotics vary. The main or root causes behind the problem can be found by the Fishbone Diagram or Ishikawa Diagram.

Here the causes behind the weight and thickness variation may include lacking of man, machine, material, method and measurement etc.

1. Sometimes man may have faster operating tendency that causes weight variation.

2. The materials sometimes are less compressed.

3. Compression time for tablets may be not highly accurate.

4. There are no proper control limits for tablet weights.

5. The coating of tablets is not uniform in many times.

\section{RECOMMENDATION}

Some recommendations may be offered to SQUARE CEPHALOSPORINS LIMITED.

1. At first they can pay their attention on what weighted \& how much thick tablets they actually want.

2. Then they should concentrate on their control limit.

3. The control limit must be not in the way they currently follow. They should use Control Chart concept for the control limit selection.

4. The control limit can be narrowed and they can practice it for both antibiotic and hormonal tablets.

5. At first they can pay their attention on what weighted \& how much thick tablets they actually want. 


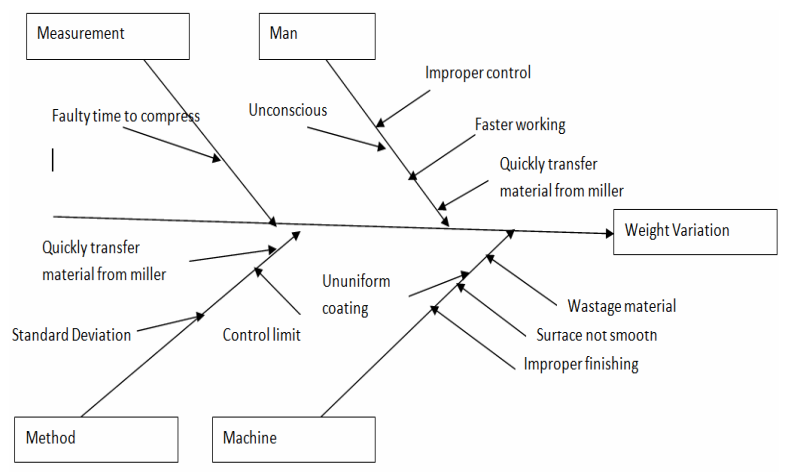

Figure 13. Fishbone diagram for weight variation

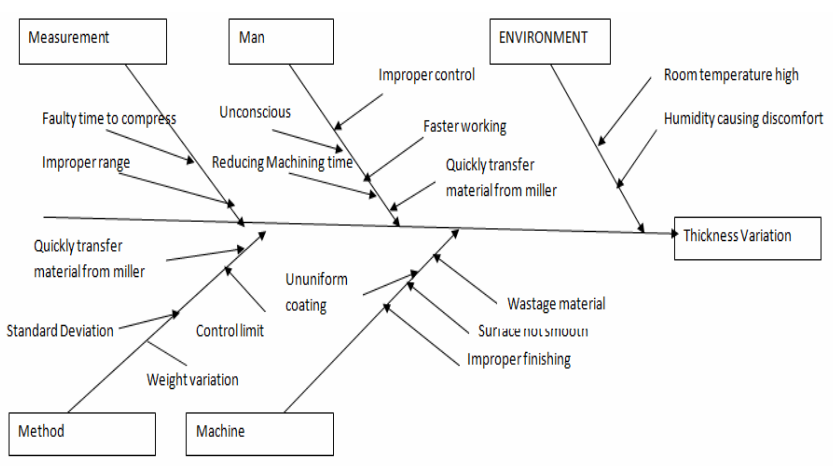

Figure 14. Fishbone diagram for thickness variation

6. At first they can pay their attention on what weighted \& how much thick tablets they actually want.

7. Then they should concentrate on their control limit.

8. The control limit must be not in the way they currently follow. They should use Control Chart concept for the control limit selection.

9. The control limit can be narrowed and they can practice it for both antibiotic and hormonal tablets.

10. The thickness of coating on tablets should be reviewed.

11. The time to compress the tablets should be known by the all operators.

12. The operators must be motivated to perform jobs in time but not faster than required time.

13. The operating environment should be reviewed.

\section{REFERENCES}

1. Ahire, S. L., Golhar, D. Y. and Waller, M. A. , 1996, "Development and validation of TQM implementation constructs", Decision Sciences, Vol. 27, No. 1, pp. 23-56.

2. Deming, W. E., 1982, Quality, Productivity and Competitive Position, Massachusetts Institute of Technology, Cambridge.

3. Deming, W. E., 1986, Out of the Crisis, Massachusetts Institute of Technology, Cambridge. 4. Feigenbaum, A. V., 1961, Total Quality Control, McGraw-Hill, New York.

5. Hauser, J. R. and Clausing, D., 1988, "The house of quality”, Harvard Business Review, Vol. 66, No. 3, pp. 63-73.

6. Ishikawa, K., 1985, What is Total Quality Control? The Japanese way, Prentice-Hall, New York.

7. Ishikawa, K., 1990, Introduction to Quality Control, 3A Corporation, Tokyo. 